\title{
BITING PERSISTENCE IN AEDES ALBOPICTUS \\ (DIPTERA: CULICIDAE)
}

\section{By}

ABEER S. YAMANY

Department of Zoology, Faculty of Science, Zagazig University, Zagazig, Egypt and

Department of Biology, Faculty of Science and Arts, Hafr Al-Batin University, Saudi

Arabia (Email: emarewan@yahoo.com)

\begin{abstract}
Mosquitoes' body size infuences a number of important factors determinants in disease transmission. Generally, high nutrition during developing stages results in large adults. The interrupted feeding of Ae. albopictus spreads zoonotic viruses.

Adult dry weight and total number of landings positively correlated with the larval nutrition represented by adult body size. Potentiality of Ae. albopictus to attack its hosts for blood meal required for egg development is an important factor in disease transmission. Although the biting persistence was described in the literature as the norm for mosquitoes, yet more study was needed. Measurement of the number of landings during a 60-min test for large and small females supplied different nutrients. Small females were significantly less persistent than larger ones. Supply of $10 \%$ sucrose solution or water $\pm 10 \%$ sucrose solution for 6 days significantly influenced biting persistence in large and small females. The pattern of persistence exhibited more increase in case of females fed $10 \%$ sucrose solution and $10 \%$ sucrose solution + water for 6 days than others fed for 4 days or 2 days, either from the high or low larval diet. This support the hypothesis that Ae. albopictus females body size influences bitting persistence.
\end{abstract}

Key words: Biting persistence, Aedes albopictus, larval nutrition, adult nutrition, body size

\section{Introduction}

Larval nutrition of mosquito controls adult body size (Fish 1985). Sugar and blood are two diet options for mosquitoes; the blood is essential for egg production, large female is more persistent to complete blood feeding successfully than small one in state of host defensive behavior (Walker and Edman, 1985) coupled with the decreased flying ability (Foster 1995), escape speed, and ability of a mosquito after a meal (Roitberg et al, 2003). Effects of blood feeding intermission and larvae food amount on growth rate of Ae. albopictus were studied in laboratory (Tsuda et al, 1992). Large females starved for 7 days caused significantly reduced persistence compared to Ae. aegypti starved for 3 days (Nasci, 1991). Brochero et al. (2006) and Xue et al. (2009) described the biting activity of Anopheles species and Ae. albopictus and found that body size affected disease transmission. Delatte et al. (2010) studied blood-feeding behavior of Ae. albopictus and found that interrupted feeding occurred when blood feeding was separated by defensive responses of host. Kamgang et al. (2012) assessed two elements of blood feeding behavior in Ae. albopictus females and found that species is extremely aggressive to humans and might be involved in man-man virus transmission. Farjana and Tuno (2013) reported that large mosquitoes have less contact with hosts, size-dependent multiple feeding influences contact frequency with hosts, and transmission was affected by body size. Manica et al. (2017) clarified possibility to foresee mean number of $\mathrm{Ae}$. albopictus females biting and found that ovitrap information can be misused to gauge number of biting. Generally, Aedes aegypti and Ae. albopictus are vectors of Dengue fever, Yellow fever, Zika fever and Chikungunya fever, increasing in the amount of blood meal would increase prevalence and incidence of virus (El-Bahnasawy et al, 2015).

Materials and Methods

Ae. albopictus were given from colony previously kept up for 15 generations in the Zoomorphology Laboratory, Cell Biology and Parasitology Institute, Heinrich Heine 
University, Düsseldorf, Germany.

Adults were reared in small wooden cages $(30 \times 30 \times 30 \mathrm{~cm})$. Two levels of larval conditions were used to control body size at adult emergence: 1- 200 larvae, high larval diet or low larval density. 2- 600 larvae, low larval diet or high larval density. Before measuring biting persistence, emerged adults were reared for $2,4 \& 6$ days at $25 \pm 1^{\circ} \mathrm{C}, 70-80 \% \mathrm{RH}$, photoperiod of 12:12 (L: D), and offered different adult diet (10\% sucrose solution, water and $10 \%$ sucrose solution + water).

For blood-feeding persistence quantification, females were separated in small cages and given 15 minutes to be adapted. Via the cage opening, a human volunteer hand was introduced. Females were not allowed to feed after landing on the host by quivering the hand and obliging to leave the host. Times number of females landed on host every five consecutive minutes was recorded for 60 minutes. As an indicator of body size, wing length was measured from the root to apex at the test end using an ocular micrometer at 25X (Gillies and de Meillon, 1968). Killed females were air-dried for two days at $85^{\circ} \mathrm{C}$ and weighed. For each treated group, mosquitoes persistence was quantified as the total number of landings in 60 -minute tested period.

Statistical analysis: Mean wing length, dry weight and total number of landings in 60minute test period $( \pm \mathrm{SE})$ of treatment groups (larval and adult diets) were compared using one-way analysis of variance (ANOVA). Analysis was done using the SPSS software.

The patterns of females biting persistence rose from two larval diets and supplied different adult diets were compared using regression analysis (Sokal and Rolf, 1981).

\section{Results}

The results showed that the wing length of all large females raised from high larval diet whether starved or offered different adult diets (i.e. water, $10 \%$ sucrose solution, water $+10 \%$ sucrose solution) was significantly $(\mathrm{P}<0.001)$ greater than small ones reared on low larval diet depicted (Tabs. $1 \& 2$ ).
Larval diet was significantly affected adult dry weight: females raised from high larval diet fed water, $10 \%$ sucrose or $10 \%$ sucrose + water for two days was $(\mathrm{P}<0.001)$ significantly greater than dry weight $(0.667 \pm$ $0.067 \mathrm{mg}, \mathrm{n}=16),(1.033 \pm 0.191 \mathrm{mg}, \mathrm{n}=16)$ and $(1.15 \pm 0.126 \mathrm{mg}, \mathrm{n}=16)$ than females raised from low larval on same diet $(0.239$ $\pm 0.0008 \mathrm{mg}, \mathrm{n}=16), \quad(0.2447 \pm 0.001 \mathrm{mg}$, $\mathrm{n}=16) \&(0.255 \pm 0.001 \mathrm{mg}, \mathrm{n}=16)$, respectively.

Dry weight of small females from low larval diet offered $10 \%$ sucrose solution only or with water for 4 days after emergence showed no significant difference (water, $0.213 \pm 0.001 \mathrm{mg}, \mathrm{n}=11 ; 10 \%$ sucrose soluteion, $0.231 \pm 0.001 \mathrm{mg}, \mathrm{n}=14$; water $+10 \%$ sucrose solution, $0.249 \pm 0.001 \mathrm{mg}, \mathrm{n}=13$ ). But, dry weight of large females from high larval diet fed $10 \%$ sucrose solution for 4 days after emergence $(0.95 \pm 0.0456 \mathrm{mg}, \mathrm{n}=14)$ was significantly more than those offered water for same period $(0.433 \pm 0.0494 \mathrm{mg}, \mathrm{n}=11)$. Large females offered 10\% sucrose solution for 6 days weighed the same as others offered $10 \%$ sucrose solution for 4 days $(0.817 \pm 0.145 \mathrm{mg}, \quad \mathrm{n}=14 ; \quad 0.95 \pm 0.0456 \mathrm{mg}$, $\mathrm{n}=14$, respectively).

Adding water to $10 \%$ sucrose solution for 2 days, 4 days $\& 6$ days did not significantly affect dry weight of large females $(1.15 \pm$ $0.1258 \mathrm{mg}, \mathrm{n}=16 ; 1.033 \pm 0.133 \mathrm{mg}, \mathrm{n}=16$; $0.92 \pm 0.111 \mathrm{mg}, \mathrm{n}=14$, respectively for each day) starvation of large $\&$ small females for 2 days post emergence significantly reduced dry weight. Access to water for 4 days after emergence gave a significant reduction $(\mathrm{P}<$ $0.01)$ in dry weight $(0.433 \pm 0.049 \mathrm{mg}, \mathrm{n}=11)$ more than for 2 days $(0.667 \pm 0.067 \mathrm{mg} n=16)$ of large females (Figs. $1 \& 2$ ). No significant differences were detected in the average dry weight of emerging females whether reared during larval stage on a high larval diet or low larval diet as an influence of the adult age have. While, adult diet have a high significant $(\mathrm{P}<0.01)$ effect on average dry weight was between starved large females for 1 days \& 2 days and large females off- 
ered water $+10 \%$ sucrose solution for 4 days \& 6 days. Largest value of dry weight was detected when females were supplied with $10 \%$ sucrose + water for 2 days. Larval diet has a highly significant $(\mathrm{P}<0.001)$ effect on the average dry weight regardless of adult diets. Large starved females for 1 days \& 2 days were found significantly $(\mathrm{P}<0.001)$ heavier than small starved females. Statistical analysis showed no significant difference in average dry weight measured for large females supplied with water, $10 \%$ sucrose solution only and water $+10 \%$ sucrose solution after 2, 4 or 6 days.

Statistically, total number of landings recorded for small females fed $10 \%$ sucrose for 2 days $(272.143 \pm 0.487)$ was same as others fed water $(300.33 \pm 1.171)$ for same period before test. Biting persistence positively correlated to adult age for all specimens supplied with $10 \%$ sucrose whether large or small. Access to $10 \%$ sucrose solution for 4 or 6day significantly increases the average total number of landings measured by 0.853 (4day $597.778 \pm 0.258, \mathrm{n}=14$; 6day, 625.833 $\pm 0.149, \quad \mathrm{n}=14) \quad(\mathrm{Y}=315+52.5 \mathrm{X}, \quad \mathrm{r}=0.853$, Slop $=52.5, \mathrm{df}=1, \mathrm{~F}=98.3$ ) for large females, and by 0.969 for small ones (4days, $321.167 \pm 0.723, \quad \mathrm{n}=14 ; \quad 6$ days, $369.333 \pm$ $0.871, \mathrm{n}=13)(\mathrm{Y}=187.5+31.25 \mathrm{X}, \mathrm{r}=0.969$, $\mathrm{Slop}=31.25, \mathrm{~F}=591.093)$. Same results were obtained when large and small females were supplied $10 \%$ sucrose with water for 4 or 6days (4days, 579.143- $\pm 0.584, \mathrm{n}=16 ; 6$ days, 644.664 $\pm 0.128, \mathrm{n}=14$ ) and (4days, $555.11 \pm 0.06, \mathrm{n}=13$; 6days, $627.83 \pm 1.342$, $\mathrm{n}=13$ ), respectively (Fig 3).

Starvation and sugar deprivation were negatively influence significantly $(\mathrm{P}<0.001)$ in relation between biting persistence and adult age. Biting persistence of starved females decreased significantly by increas-ing adult age from one to two days (for large females, 1 day $255.571 \pm 0.296, n=16$; 2 days $185.571 \pm 0.313, \mathrm{n}=10$ and for small females, 1 day, $193.5 \pm 0.214, \mathrm{n}=16 ; 2$ days 126.833 $\pm 0.154, \mathrm{n}=9)$. Biting persistence of water fed females decreased significantly by increasing adult age from 2 to 4days (2days, $300.33 \pm 1.171, \mathrm{n}=16 ; 4$ days $247.5 \pm 1.997$, $\mathrm{n}=11$ for large females, 2days $236.167 \pm$ $0.14, \mathrm{n}=16$; 4days $152.833 \pm 0.179, \mathrm{n}=11$ for small females). No significant difference $(\mathrm{P}>0.05)$ was in total number of landings in water fed-large females for 4 days (247.5 $\pm 1.997, \mathrm{n}=11$ ) as compared to starved large females for 1day $(255.571 \pm 0.296, \mathrm{n}=16)$. A decrease total number of landings recorded significantly in females fed water only by increasing the female age from 2 to 4 days.

A significant increase in females fed $10 \%$ sucrose solution and water $+10 \%$ sucrose solution increased female age from 2 to 4 to 6 days $(\mathrm{P}<0.001)$. Large Ae. albopictus fema les were significantly more persistent than small ones regardless of whether the females were starved or fed different types of food.

Table 1: Wing length, body dry weight \& total number of landings/group in Ae. albopictus (Skuse) raised from high level of larval diet during 60-min under laboratory conditions $\left(25 \pm 1^{\circ} \mathrm{C}, 70-80 \%\right.$ R.H.\& D: L, 12: 12$)$.

\begin{tabular}{|c|c|c|c|c|c|}
\hline Adult diet & Age (days) & Number & Wing length $(\mathrm{mm})$ & Dry weight (mg) & Total number of landings/group \\
\hline Starved & 1 & 16 & $3.614 \pm 0.079$ & $0.517 \pm 0.017$ & $255.571 \pm 0.296$ \\
\hline Starved & 2 & 10 & - & $0.26 \pm 0.079$ & $185.571 \pm 0.313$ \\
\hline Water & 2 & 16 & $3.617 \pm 0.0946$ & $0.667 \pm 0.067$ & $300.33 \pm 1.171$ \\
\hline Water & 4 & 11 & - & $0.433 \pm 0.049$ & $247.5 \pm 1.997$ \\
\hline $10 \%$ sucrose solution & 2 & 16 & $3.675 \pm 0.0796$ & $1.033 \pm 0.191$ & $443.3 \pm 0.173$ \\
\hline $10 \%$ sucrose solution & 4 & 14 & - & $0.95 \pm 0.0456$ & $597.778 \pm 0.258$ \\
\hline $10 \%$ sucrose solution & 6 & 14 & - & $0.817 \pm 0.145$ & $625.833 \pm 0.149$ \\
\hline Water $+10 \%$ sucrose & 2 & 16 & $3.686 \pm 0.079$ & $1.15 \pm 0.126$ & $526.167 \pm 0.182$ \\
\hline Water $+10 \%$ sucrose & 4 & 16 & - & $1.033 \pm 0.133$ & $579.143 \pm 0.584$ \\
\hline Water $+10 \%$ sucrose & 6 & 14 & - & $0.92 \pm 0.111$ & $644.664 \pm 0.128$ \\
\hline
\end{tabular}

\section{Discussion}

Total number of landings during 60-minute test period was influenced significantly by larval diet, while pattern of biting persis- tence is affected significantly by adult diet in Ae. albopictus.

Larger females produced from high larval diet had more significant number of landings 
Table 2: Wing length, body dry weight \& total number of landings/group in Ae. albopictus (Skuse) raised from low level of larval diet during 60-min under laboratory conditions $\left(25 \pm 1^{\circ} \mathrm{C}, 70-80 \%\right.$ R.H. \& D: L, 12:12).

\begin{tabular}{|c|c|c|c|c|c|}
\hline Adult diet & Age (days) & Number & Wing length $(\mathrm{mm})$ & Dry weight $(\mathrm{mg})$ & Total number of landings/group \\
\hline Starved & 1 & 16 & $2.7167 \pm 0.0654$ & $0.189 \pm 0.001$ & $193.5 \pm 0.214$ \\
\hline Starved & 2 & 9 & - & $0.138 \pm 0.001$ & $126.833 \pm 0.154$ \\
\hline Water & 2 & 16 & $2.708 \pm 0.0534$ & $0.239 \pm 0.001$ & $236.1667 \pm 0.14$ \\
\hline Water & 4 & 11 & - & $0.213 \pm 0.001$ & $152.833 \pm 0.1796$ \\
\hline $10 \%$ sucrose solution & 2 & 16 & $2.785 \pm 0.031$ & $0.245 \pm 0.001$ & $272.143 \pm 0.487$ \\
\hline $10 \%$ sucrose solution & 4 & 14 & - & $0.231 \pm 0.001$ & $321.167 \pm 0.723$ \\
\hline $10 \%$ sucrose solution & 6 & 13 & - & $0.228 \pm 0.007$ & $369.333 \pm 0.871$ \\
\hline Water +0\% sucrose & 2 & 16 & $2.693 \pm 0.03$ & $0.255 \pm 0.001$ & $378 \pm 0.556$ \\
\hline Water+10\% sucrose & 4 & 13 & - & $0.249 \pm 0.001$ & $555.11 \pm 0.06$ \\
\hline Water+10\% sucrose & 6 & 13 & - & $0.234 \pm 0.009$ & $627.83 \pm 1.342$ \\
\hline
\end{tabular}

than smaller and lighter females raised from low larval nutrition. Females offered access to water only or $10 \%$ sucrose solution only for 2days before testing had significantly the same biting persistence. Similar results were reported for Ae. aegypti (Klowden et al, 1988) and for Ae. triseriatus (Walker and Edman, 1985).

Heavier females raised from high larval diet had a greater number of landings, a higher success rate of feeding on blood and more host seeking behavior than lighter females rose from low larval diet regardless of the adult diet. Besides, heavier females are more persistence than lighter ones and were more able to complete blood feeding successfully. Same results were reported for $A e$. triseriatus (Walker and Edman, 1985), for Ae. aegypti (Klowden et al, 1988; Nasci, 1991) and for Ae. albopictus (Tsuda et al, 1992). On the contrary, Farjana and Tuno (2013) claimed that the biting persistence and host-seeking behavior were negatively correlated to body size and large females have less contact with hosts.

Biting persistence of all heavier and lighter females were influenced significantly by the access to water only, $10 \%$ sucrose solution only or adding both for 4 or 6 days, while the dry weight are not influenced. Severe starvation of mosquito females significantly reduced total number of landings and the body dry weight regardless of females' size of. Also, when females were offered water only for 4 days, they were less persistent than those that fed $10 \%$ sucrose solution and $10 \%$ sucrose solution plus water. Walker and Edman (1985) found that sugar fed fem- ale Ae. triseriatus was more persistent than starved ones. Nasci (1991) found that body dry weight and biting persistence of large females were not altered by access to sucrose for 3 or 7. Severe starved females Ae. aegypti significantly influenced total number of landings.

In the present study, pattern of landings was influenced mainly by adult diet regardless of its age or size. A high level of persistence maintained relatively for all mosquitoes offered water $+10 \%$ sucrose solution for a longer time than others fed water or $10 \%$ sucrose solution alone. Adult body size was positively correlated with persistence and nutrient contents. Large females achieved a successful blood meal within the shortest time span. But, duration of starvation was negatively correlated with adult body size; this was consistent with the hypothesis that biting persistence controlled by stored nutrient levels for Ae. aegypti (Nasci, 1991). Van Handel and Day (1988) found that lipid and glycogen reserved affect positively on wing length of Ae. vexans (Meigen). Nasci (1991) discovered that large Ae. aegypti adults raised from high larval diets, emerged with higher caloric reserves than smaller raised from low larval diets. Van Handel (1971) stated that energy source for mosquito flight depended primary on stored glycogen in tissue during larval stage, adult size-related variation correlated with larval diet and nutrient reserves, a primary factor control biting persistence. Edman and Lynn (1975) and Nayer and Sauerman (1975a,b) showed that after a blood meal carbohydrate withdrawal reduced females number that gave mature 
eggs and reduced number of subjects to behavioral inhibition that accompanied oocyte development. Steinwascher (1982) reported that large female body size correlated with increased biting persistence and increased female longevity and starvation resistance.

\section{Conclusion}

Biting persistence positively correlated with adult nutrition and body size. Large mosquitoes females have more contact with hosts and thus more prevalence of viral hemorragic fevers

\section{References}

Brochero, H, Pareja, PX, Ortiz, G, Olano, V A, 2006: Breeding places and biting activity of Anopheles species in the municipality of Cimitarra, Santander, Colombia. Bioméd. 26, 2:26977.

Delatte, H, Desvars, A, Bouétard, A, Bord, S, Gimonneau, G, et al, 2010: Blood-feeding behavior of Aedes albopictus, a vector of Chikungunya on La Réunion. Vector Borne Zoonotic Dis. 10, 3:249-58.

Edman JD, Lynn HC, 1975: Relationship between blood meal volume and ovarian development in Culex nigripalpus (Diptera: Culicidae). Entomol. Exp. Appl. 18:261-8

El-Bahnasawy, MM, Megahed, LA, Saleh, H AA, Morsy, TA, 2015: Training program for the nursing staff regarding the viral hemorrhagic fevers (VHFs) in a fever hospital. J. Egypt. Soc. Parasitol. 45, 2:249-72

Farjana, T, Tuno, N, 2013: Multiple blood feeding and host-seeking behavior in Aedes aegypti and Aedes albopictus (Diptera: Culicidae). J. Med. Entomol. 50, 4:838-46

Fish, D, 1985: An analysis of adult size variation within natural mosquito populations. Ecology of mosquitoes: Proceed. a Workshop Florida Med. Entomol. Lab. Vero Beach FL, USA.

Foster, W, 1995: Mosquito sugar feeding and reproductive energetics. Ann. Rev. Entomol. 40: 443-74

Gillies, MT, de Meillon, B, 1968: The Anophelines of Africa south of the Sahara. Inst. Med. Res. 54:343.

Kamgang, B, Nchoutpouen, E, Simard, F, 2012: Notes on the blood-feeding behavior of Aedes albopictus (Diptera: Culicidae) in Cameroon. Parasit. Vectors 5:57.

Klowden, MJ, Blackmer, JL, Chambers, G M, 1988: Effects of larval nutrition on the host- seeking behavior of adult Aedes aegypti mosquitoes. J. Am. Mosq. Control Assoc. 4:73-5

Manica, M, Rosà, R, Torre, AD, Caputo, B, 2017: From eggs to bites: do ovitrap data provide reliable estimates of Aedes albopictus biting females? J. Life Environ. Sci. 5:e2998

Nasci, RS, 1990: Relationship of wing length to adult dry weight in several mosquito species (Diptera: Culicidae). J. Med. Entomol. 27:716-9. Nasci, RS, 1991: Influence of larval and adult nutrition on biting persistence in Aedes aegypti (Diptera: Culicidae). J. Med. Entomol. 28, 4: 522-6

Nayar, JK, Van Handel, E, 1971: The fuel for sustained mosquito flight. J Insect Physiol. 17: 471-81

Nayar, JK, Sauerman, DM, 1975a: The effect of nutrition on survival and fecundity in Florida mosquitoes. Part 1: Utilization of blood meal for survival. J. Med. Entomol. 12:92-8.

Nayar, JK, Sauerman, DM, 1975b: The effe ct of nutrition on survival and fecundity in Florida mosquitoes. Part 2: Utilization of sugar for survival. J. Med. Entomol. 12:99-103

Roitberg, B, Mondor, E, Tyerman, J, 2003: Pouncing spider, flying mosquito: blood acquisition increases predation risk in mosquitoes Behav. Ecol.14:736-40

Sokal, RR, Rolf, FJ, 1981: Biometry: Principles and Practice of Statistics in Biological Research. $2^{\text {nd }}$ ed.; Freeman, New York.

Steinwascher, K, 1982: Relationship between pupal mass and adult survivorship and fecundity for Aedes aegypti. Environ. Entomol. 11:150-3

Tsuda, Y, Takagi, M, Wada, Y, 1992: Laboratory study on the effects of blood feeding intermission and food amount for larvae on the population growth of Aedes albopictus (Diptera: Culicidae). Japn. Soc. Med. Entomol. Zool. 43, 2: 89-93.

Van Handel, E, Day, JF, 1988: Assay of lipid, glycogen and sugars in individual mosquitoes: Correlations with wing length in field-collected Aedes vexans. J. Am. Moq. Control Assoc. 4: 549-50

Walker, ED, Edman, JD, 1985: The influence of host defensive behavior on mosquito (Diptera: Culicidae) biting persistence J. Med. Entomol. 22:370-2

Xue, R, Barnard, DR, Ali, A, 2009: Influence of multiple blood meals on gonotrophic dissociation and fecundity in Aedes albopictus. J. Am. Moq. Control Assoc. 25, 4:504-7 


\section{Explanation of figures}

Fig 1: Adult dry weight (mg) of Ae. albopictus (Skuse) females fed different adult diets and raised from low and high levels of larval diet under laboratory conditions $\left(25 \pm 1^{\circ} \mathrm{C}, 70-80 \%\right.$ R.H. $\&$ D: L, $\left.12: 12\right)$.

Fig.2: Total number of landings/group during 60-min measurements of biting persistence in Ae. albopictus (Skuse) fed different adult diets and raised from low and high levels of larval diets under laboratory conditions $\left(25 \pm 1^{\circ} \mathrm{C}, 70-80 \%\right.$ R.H. \& D: L, $\left.12: 12\right)$.

Figs. 3-6: Total number of landings during 60-min period for large Ae. albopictus females tested for treatment combination of high larvel diet/adult diet (water $+10 \%$ sucrose solution), regression formula: $\mathrm{Y}=$ number of landings, $\mathrm{X}=$ adult age, and $\mathrm{r}=$ correlation coefficient, $\mathrm{R}$ $\mathrm{Sq}$ Linear $=0.959$. Slops of regression formula showed a significant difference $(\mathrm{P}<0.05)$. Triangles showed number of landings per adult age for each individual tested. Line $=$ formula shown as solid line via data under laboratory conditions $\left(25 \pm 1^{\circ} \mathrm{C}, 70-80 \%\right.$ R.H. and D: L, $\left.12: 12\right)$.
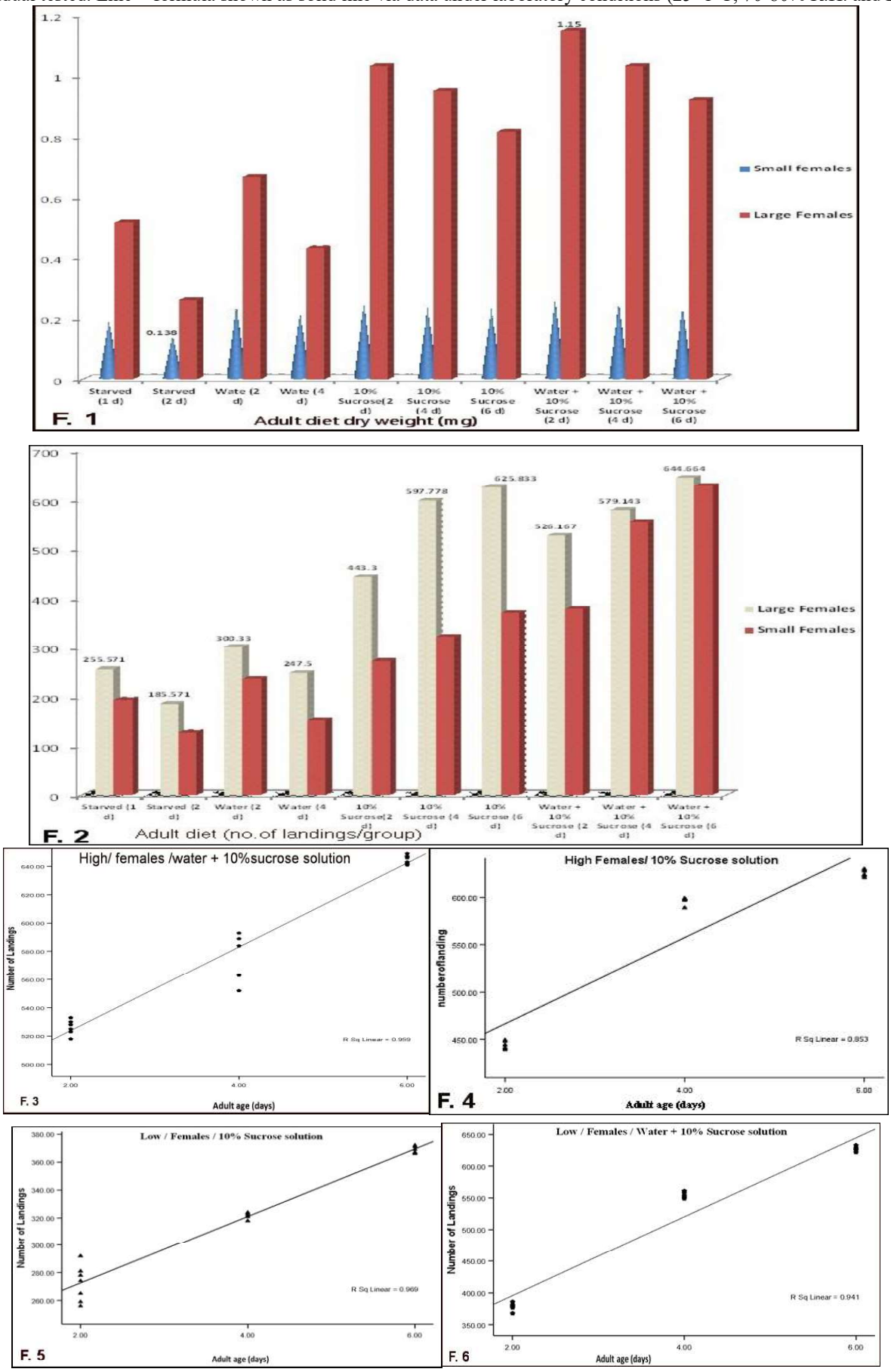